\title{
Characterization of the microstructural components and corrosion-induced changes in the mechanical properties of oolitic limestone
}

\author{
Aránzazu Piñán-Llamas ${ }^{1,}$, Fawad S. Niazi ${ }^{2}$, Colton Amstutz ${ }^{2}$, and Zachary Brown ${ }^{2}$ \\ ${ }^{1}$ Construction Engineering Technology, School of Polytechnic, Purdue University Fort Wayne, 2101 East Coliseum Blvd., Fort \\ Wayne, IN 46805, USA \\ ${ }^{2}$ Department of Civil and Mechanical Engineering, Purdue University Fort Wayne, 2101 East Coliseum Blvd., Fort Wayne, IN \\ 46805, USA
}

\begin{abstract}
The understanding of the variation of mechanical properties and microstructural changes of rocks due to chemical weathering is critical for prospection, extraction and storage of energy resources in the subsurface. Uniaxial and triaxial compression tests were conducted on fresh and chemically weathered oolitic limestone samples submerged in acidic solutions with $\mathrm{pH} 5$ and $\mathrm{pH} 3$ values for 30 and 50 days each. Results show that both, acid concentration and exposure period have a significant influence not only in changes of effective porosity, Young's modulus and peak strength, but also in the development of stress-induced microstructures. While the change in effective porosity increased and the Young's modulus decreased with exposure time, the peak strength decreased with exposure time and decreasing $\mathrm{pH}$. Micro-fracturing, twinning, and rigid body rotation were the main mechanisms of the deformations observed. The highest density of microcracks and twinned grains were observed in samples subjected to longer exposure periods of time, suggesting that the exposure time constitutes an essential factor in rock softening. Microfracturing initiated at grain boundaries, where stress concentrations were higher. In agreement with previous work on limestone inelastic compaction, the mechanical contrast of allochemical components with respect to cement conditioned the spatial distribution of the microfractures.
\end{abstract}

\section{Introduction}

Rocks in contact with underground water with different $\mathrm{pH}$ values and chemistry are subjected to changes at the macro and microscopic level, such as an increase in porosity and/or micro-structure weakening $[1,2]$. These changes may degrade the rock and modify its mechanical properties, such as a decrease in compressive strength and elastic modulus. Chemical degradation in combination with variations in external loads or pore pressure reduction can accelerate rock failure [3, 4] causing significant negative economic, and environmental impact in energy georeservoirs (i.e. during hydrocarbon exploration and production, the use of geothermal reservoirs, changes in underground thermal energy storage systems or $\mathrm{CO}_{2}$ capture and geologic sequestration). Therefore, studies on rock interaction with fluids under stress are important to enhance our understanding of the mechanical response of the in-situ rock mass hosting energy resources and to predict and control its behavior.

Limestone is relatively soluble and chemically reactive when in contact with acidic water containing different ions. Moreover, external stresses may generate microcracks in the rock that can enhance the path of acidic water amplifying the chemical effects on degradation and failure [2]. Several studies have been conducted on the mechanical properties of limestone under external stress that describe the characteristics of mechanical deformation curves $[5,6]$ and the micromechanics of brittle faulting and compactive cataclastic flow $[5,7,8]$. Those studies have shown that in porous carbonates, a variety of micro-mechanisms such as pore collapse, grain crushing, crystal plasticity and pressure solution can lead to inelastic compaction $[7,8]$. Due to the interplay between multiple coexisting deformation processes, the predominant mechanisms responsible for failure are still not well understood.

The studies on the effects of chemical on mechanical properties of limestone under external loading are less numerous and mostly involve injection of a $\mathrm{CO}_{2}-$ rich brine or gas in the samples during the triaxial tests $[9$, 10] or saturation [11] or submersion of samples in water [5] or other reactive fluids $[12,4,2]$.

Although previous studies have contributed to the understanding of the influence of chemicals on the mechanical properties of limestone, not many have conducted direct microstructural observations of the

\footnotetext{
* Corresponding author: pinana@pfw.edu
} 
damage intensity of the samples fractured in compression test after their chemical weathering. Since the effects of chemical solutions in limestone occur at microscale and greatly influence macro-mechanical changes, it is of great importance to characterize the micro-damage.

Presented in this paper are the preliminary findings of the changes in the mechanical properties recorded during a series of uniaxial and triaxial tests on the samples of oolitic limestone chemically weathered by subjecting them to reactive fluids of different acidity and exposure durations. Observations at the microscopic level related to the distribution, orientation and density of microcracks and twinning in samples are reported

\section{Ste. Genevieve Limestone}

Samples of the Ste. Genevieve Limestone were used in this study. It is part of a Mississipian carbonate sequence that crops mostly in South and Central Indiana [13]. Despite the fact that Ste. Genevieve Limestone is one of the primary karst-forming units in Indiana [14], little work has been done to characterize its physical and mechanical properties through experimental deformation studies.

According to their main constituents: micrite (microcrystalline carbonate with $<4 \mu \mathrm{m}$ in diameter), sparite (crystalline carbonate with grain diameters of $>10$ $\mu \mathrm{m})$ and allochemicals (grains that have been locally transported, including ooliths, bioclasts, intraclasts or peloids), the studied samples are classified as sparry allochemical limestone [15]. Based on petrographic observations, ooliths constitute $\sim 69 \%$ of the bulk rock volume in the samples, while the other allochemical components are fossils, pellets and lumps. Estimations of the total percentage of allochems and typical ranges of grain sizes are shown in Table 1.

Most of the allochems are coated with a very thin layer of micrite and only locally some allochems show interpenetrated borders as a result of compaction. Open pores and interstices in fossils are filled with sparry cement. The allochemical components are embedded in mostly sparite cement or microsparite, although some micrite is also present.

The total porosity of intact samples was calculated after they were oven-dried at $110^{\circ} \mathrm{C}$ for a minimum of 48 hours. The dry samples were weighted, and then saturated with water under vacuum for 24 hours. The difference between the saturated and dry weight taken as the weight of the water absorbed by the samples was divided by the unit weight of water. The interconnected or effective porosity thus calculated for these samples is low, ranging between 3.47 to $4.06 \%$ (Table 1).

\section{Experimental procedures}

\subsection{Sample preparation}

The investigations were performed on five $38.1 \mathrm{~mm}(1.5$ in) diameter cylindrical cores with lengths of $76.2 \mathrm{~mm} \mathrm{(3}$ in) that were cored perpendicular to the sedimentary bedding.
Table 1. Main petrographic characteristics of the samples used in this study.

\begin{tabular}{ccccc}
\hline Sample & $\begin{array}{c}\text { Allochems } \\
(\%)\end{array}$ & $\begin{array}{c}\text { Grain size } \\
\text { range }(\mathrm{mm})\end{array}$ & $\begin{array}{c}\text { Average } \\
\text { grain size } \\
(\mathrm{mm})\end{array}$ & $\begin{array}{c}\text { Initial } \\
\text { Effective } \\
\text { Porosity (\%) }\end{array}$ \\
\hline $3-1$ & 79.20 & $0.089-1.47$ & 0.5 & 3.48 \\
$3-2$ & 76.02 & $0.103-1.51$ & 0.41 & 3.53 \\
$3-3$ & 78.35 & $0.129-1.89$ & 0.47 & 4.06 \\
$3-4$ & 80.20 & $0.15-1.75$ & 0.4 & 3.49 \\
$3-5$ & 82.10 & $0.055-4.5$ & 0.46 & 3.47 \\
\hline
\end{tabular}

Selected samples were submerged in solutions with two different $\mathrm{pH}$ values ( 3 and 5) for two designated different durations (30 and 50 days, as listed in Table 2). The $\mathrm{pH} 3$ solution was prepared by diluting a mixture of chloroacetic acid $\left(\mathrm{C}_{2} \mathrm{H}_{3} \mathrm{ClO}_{2}\right)$ with sodium hydroxide $(\mathrm{NaOH})$ in distilled water, whereas for the $\mathrm{pH} 5$ solution a mixture of glacial acetic acid $\left(\mathrm{CH}_{3} \mathrm{COOH}\right)$ with sodium hydroxide was diluted in distilled water. The $\mathrm{pH}$ of the solutions with the submerged samples was observed daily to ensure that the values were maintained within a \pm 0.1 range. After their designated submersion periods, the changed values of the effective porosities of the samples were obtained in the manner explained above (see Table 2 for the values).

\subsection{Testing process}

After determining the porosity, the samples were ovendried for at least 24 hours $\left(110^{\circ} \mathrm{C}\right)$. Upon cooling down to room temperature samples were jacketed in rubber membranes and subjected to triaxial compression in a Hoek cell placed within the loading frame. A confining pressure of $25 \mathrm{MPa}$ was maintained in the Hoek cell during each test. Following the method specified in ASTM D7012-14, the axial stresses $\left(\sigma_{1}\right)$ were applied at a constant strain rate to produce failure in compression between 2 and 15 minutes. In all cases, the differential stress increased at the specified strain rate until the samples failed.

Additionally, a fresh core sample (sample 3-1, Table 1) was uniaxially tested in compression until failure, so that the microstructures could be compared with those developed in corroded and triaxially tested samples. It is important to mention that sample 3-1 was used primarily to determine the initial state of porosity and to study the microstructures in the fresh (unweathered state) to have a basis for comparison of the changes at that level after the respective designated weathering conditions were applied.

\subsection{Microstructural analysis}

The deformed samples were impregnated under vacuum with a low-viscosity epoxy containing a fluorescent dye and standard petrographic thin sections were made from their central vertical plane. Therefore, the thin sections were cut perpendicular to bedding and with the longest dimension parallel to $\sigma_{1}$. The thin sections were also normal to the main fault (fracture) surface. The microstructures of the deformed samples were studied 
Table 2. Results of the compression tests related to the testing conditions used in this study.

\begin{tabular}{|c|c|c|c|c|c|c|}
\hline Sample \# & $\mathrm{pH}$ & $\begin{array}{l}\text { Time } \\
\text { (days) }\end{array}$ & $\begin{array}{l}\text { Change in effective porosity } \\
\text { (at } 30 \text { or } 50 \text { days) }(\%)\end{array}$ & $\begin{array}{c}\text { Confining Pressure } \\
(\mathrm{MPa})\end{array}$ & $\begin{array}{l}\text { Peak Stress } \\
\sigma_{1}-\sigma_{3},(\mathrm{MPa})\end{array}$ & $\begin{array}{c}\text { Elastic } \\
\text { Modulus }(\mathrm{GPa})\end{array}$ \\
\hline $3-2$ & 5 & 30 & 12.64 & 25 & 194.4 & 13.12 \\
\hline $3-3$ & 5 & 50 & 29.82 & 25 & 184.11 & 12.39 \\
\hline $3-4$ & 3 & 30 & 19.28 & 25 & 182.23 & 12.42 \\
\hline $3-5$ & 3 & 50 & 44.03 & 25 & 177.27 & 11.56 \\
\hline
\end{tabular}

under both, a fluorescence and a polarizing petrographic microscope. Damage measurements were done on twodimensional (2-D) thin sections. Thus, the analysis presented here is based on 2-D approximations.

Quantitative analysis in the allochem content was performed in 10 digital images (obtained with a camera mounted on the polarizing microscope), covering approximately $200 \mathrm{~mm}^{2}$ of each thin section. The main goal was to study the presence of possible heterogeneities in the studied samples and its influence in their damage. The calculations were done with the Threshold function of ImageJ, a public domain image-processing program developed at the National Institutes of Health. Using the same software, the orientation of the long axis of at least 2000 allochems per sample was measured with respect to bedding. The objective was to determine the presence of possible allochem preferred orientations with respect to $\sigma_{1}$ after deformation.

The microstructural study also included the analysis of the mode, dimensions, density and distribution of stress-induced microfractures in the deformed samples. Microstructural mapping of microfractures was conducted by simultaneous manual digitization of images taken with a camera mounted on the fluorescence microscope $(\times 4$ and $\times 10$ magnification) and visual examination of fractures on the petrographic microscope.

The shortest resolvable fractures were $\sim 0.01 \mathrm{~mm}$, while the largest fractures measured were $\sim 2 \mathrm{~mm}$. For each sample (thin section), the microfracture density was calculated as the cumulative length of all mapped microfractures per unit area $\left(\mathrm{mm} / \mathrm{mm}^{2}\right)$. The size of the mapped area per thin section was at least $30 \mathrm{~mm}^{2}$.

The intensity of twinning was also characterized. For each thin section, at least 64 optical micrographs were taken in randomly selected areas at X10 magnification.

Following Vajdova et al., [7], the number of twinned grains was normalized by the investigated area to obtain a semi-quantitative number (twinning density).

\section{Experimental Results}

Figure 1 shows the stress-strain curves of the triaxial tests and the results are summarized in Table 2. As shown, the sample submerged longer in the more acidic solution $(\mathrm{pH} 3)$ reached the lowest peak stress before failure and

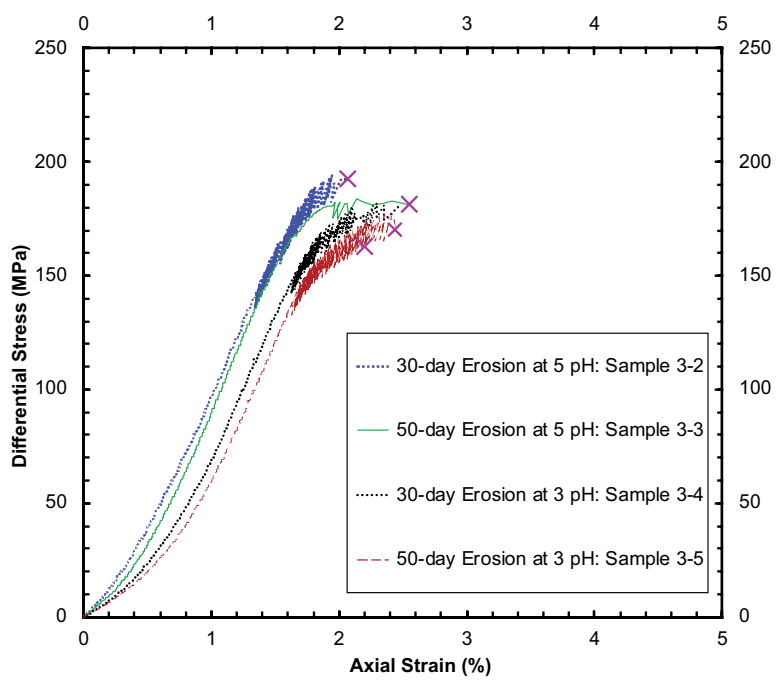

Fig. 1. Differential stress $\left(\sigma_{1}-\sigma_{3}\right)$ versus axial strain for the triaxially compressed samples of Ste. Genevieve Limestone.

shows the lowest Young's modulus value (i.e., it has softened up to the maximum of all the samples). That particular sample also experienced the highest change in effective porosity (Table 2). In general, the peak strength decreases with increasing acidity and submersion time. The decrease in the Young's modulus and increase in effective porosity are more pronounced with a longer period of exposure (50 days) in acidic solution. The sample submerged in a $\mathrm{pH} 5$ solution for 50 days has a similar Young Modulus than the sample submerged for 30 days in a $\mathrm{pH} 3$ solution, although their change in effective porosity differs by $\sim 10 \%$.

\section{Microstructural observations}

The main mechanisms of deformation observed in our samples are stress-induced microcracking and twinning. Both, microfracture and twinning densities increase with the exposure duration. In all samples, high fracture and twin density are mostly localized in proximity to the main faulted planes.

Damage resulting from uniaxial testing in the fresh sample is mostly associated to tensile fracturing. The fractures are predominantly subparallel to $\sigma_{1}$, but other

\footnotetext{
* Corresponding author: pinana@pfw.edu
} 
Table 3. Results of the microstructural damage analysis

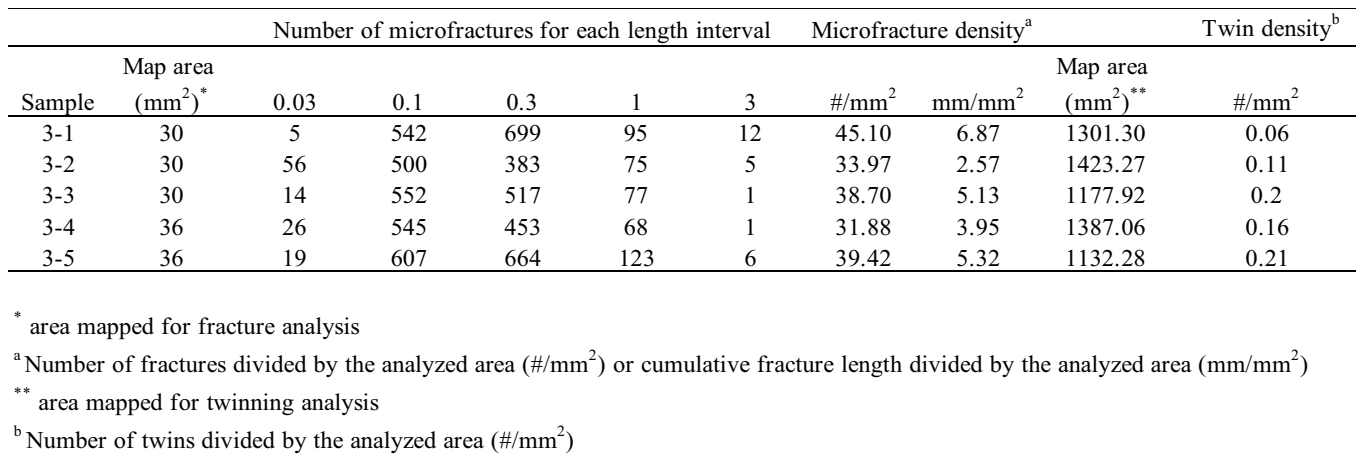

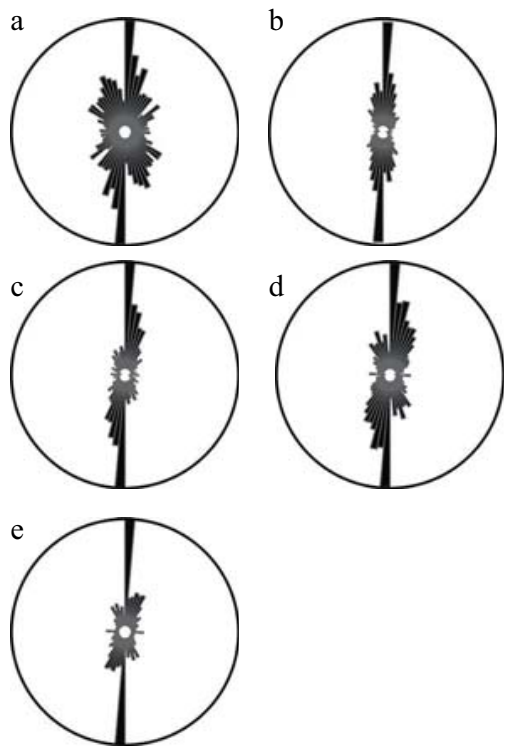

Fig. 2. Rose diagrams showing the distribution of microfracture orientation and frequency in the analyzed samples. The orientation of $\sigma_{1}$ is vertical and $\sigma_{3}$ is horizontal. The azimuth interval is $5^{\circ}$. (a) 3-1: uniaxially tested sample $(\mathrm{n}=1354)$; (b) sample 3-2 ( $\mathrm{n}=1018)$; (c) sample 3-3 $(\mathrm{n}=1150)$; (d) sample 3$4(\mathrm{n}=1094) ;(\mathrm{e})$ sample 3-5 $(\mathrm{n}=1418)$.

orientations are also present (Figure 2). Fractures are intergranular, intragranular and transgranular (Figure 3a) and vary in scale from $<0.1 \mathrm{~mm}$ to $\sim 12 \mathrm{~mm}$. The microfracture density is the highest in thefresh samples tested in uniaxial compression, and the fractures are longer than in triaxially tested samples (Table 3).

Intragranular fractures developed either inside of elongated allochems oriented sub-parallel or subperpendicular to $\sigma_{1}$ or along discontinuities inside of grains, such as the interface between the micritic layering of ooliths and their sparitic cores. In general, cracks nucleated and propagated from impinging grain-to-grain contacts or from grain-to-cement contacts, where stress concentrated. The number of twinned calcite grains was significantly lower (Table 3 ) and their size was much smaller than in the weathered triaxially tested samples.

Generally, the fractures in triaxially tested samples are shorter than in the uniaxially tested sample (Figure $3 b$, c, d, f). Within the triaxially tested samples, those that were submerged for longer periods of time exhibit the largest microfracture densities (samples 3-3 and 3-5, Table 3). The microfracture density varies in space within each sample. For example, the maximum local density of a subregion is sample $3-5$ is $\sim 11 \mathrm{~mm} / \mathrm{mm}^{2}$ while the mean density for the sample is $5.32 \mathrm{~mm} / \mathrm{mm}^{2}$.

The majority of fractures in triaxially tested samples are oriented subparallel to the direction of maximum compressive stress, $\sigma_{1}$ (Figure 3 ). Some of the shear fractures show a small offset (displacement) and may form dilational jogs where segments overlap (Figure 4e).

In the triaxially tested samples, transgranular fractures are generally fewer and much shorter than in the uniaxially tested samples. Short intragranular fractures or fractures confined to cemented areas are the most common. Cracks nucleated from grain-to-grain or from grain-to-cement contacts. In samples with longer weathering periods, fractures at relatively high angles with respect to the sample axis show deflections to become subparallel to $\sigma_{1}$ and wing-cracks are common (Figure 3b). These two samples accommodated deformation by the development of closely spaced fractures in cement areas or, very locally, by internal shearing of allochems (Figure $3 \mathrm{c}$ ). Although there is no precise linear correlation between peak strength and twinning density, the sample that reached the lowest peak strength shows the highest twinning density and the sample with the highest peak strength shows the lowest twinning density. Twins in calcite grains are often crosscut by fractures (Figure $3 b, c, d, f$ ).

\section{Discussion}

In this work, results of experimental research on the effects of dissolution in the mechanical properties of limestone are presented. The data show a general increase of the change in effective porosity with exposure duration. Samples submerged for 50 days show the highest porosity. One way of quantifying micro-damage using porosity is to calculate the damage variable $\mathrm{D}$ defined by Kachanov [16] as:

$D=\frac{n-n_{0}}{1-n_{0}}$

\footnotetext{
* Corresponding author: pinana@pfw.edu
} 

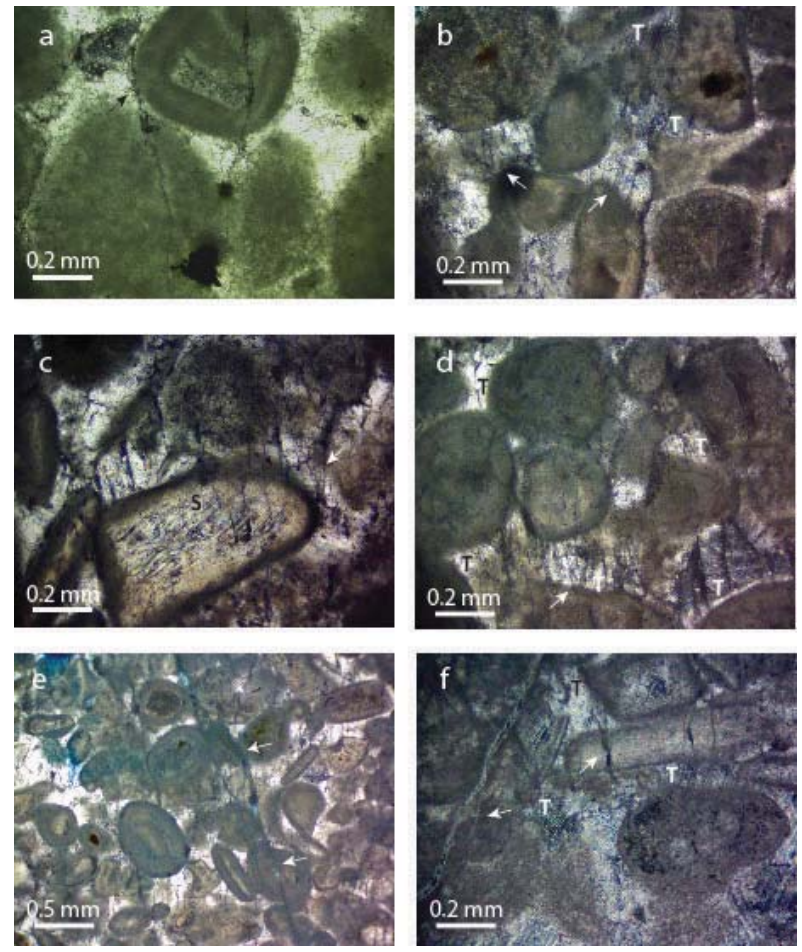

Fig. 3. Microphotographs under cross-polarized light showing the distribution of microfractures and twinning in selected analyzed samples: (a) milimetric-scale transgranular fractures in the uniaxially deformed sample (locally they propagate along grain boundaries (arrowed); (b) fractures localized in cemented areas in the triaxially deformed sample that was submerged for 50 days in a $\mathrm{pH} 5$ solution (the fractures propagate from grain boundaries (arrowed) and twinned calcite (cemented areas) are common (T); (c) sheared fossil (S) in the same sample, with microfractures crosscutting the sigmoidal microstructures (closely spaced fractures seem to originate at grain boundaries (arrowed); (d) closely spaced microfractures subparallel to $\sigma_{1}$ showing micro-displacements (arrowed) in the triaxially deformed sample submerged for 50 days in a solution with $\mathrm{pH} 3$ (the microfractures are crosscutting twinned cemented areas); (e) millimetric-scale shear fracture showing relative displacement in a fossil (arrowed) and overstepping segments (extensional jog) (the sample was submerged for 50 days in a solution with $\mathrm{pH} 5$ ); (f) microfractures (arrowed) with wingcracks and twinned (T) calcite grains in the sample submerged for 30 days in a solution with $\mathrm{pH} 5$. Note: The direction of $\sigma_{1}$ is vertical and $\sigma_{3}$ is horizontal for all samples.

where $\mathrm{n}_{0}$ is the initial porosity of the sample, and $\mathrm{n}$ is the porosity of the sample after external damage such as chemical corrosion. It can be observed that the microdamage within the samples submerged for longer periods are greater (Figure 4).

Longer exposure durations (in addition to the acidity of the solutions) also influenced the mechanical properties of the samples, since the rock stiffness was reduced with increasing duration. The peak strength decreased with increasing duration and decreasing $\mathrm{pH}$. However, the sample submerged in a $\mathrm{pH} 3$ solution for 30 days (sample 3-5) showed a similar peak strength when compared with

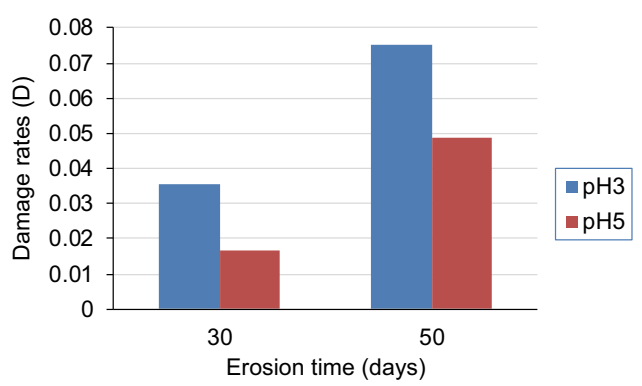

Fig. 4. Damage rates (D) of the studied samples.

the sample submerged for 50 days in a solution with $\mathrm{pH} 5$ (sample 3-3). This occurred even though sample 3-3 had a larger percentage of porosity (and an $\sim 10 \%$ larger increment of the effective porosity) with respect to sample 3-5 overall. This suggests that the strength of the rocks is not entirely attributed to the porosity change, but there are also other deteriorations of the sample microstructure, for instance changes in the inter-granular cementation. This is in agreement with observations from other authors that state that microscopic structure changes such as growth of discontinuities, softening of the skeleton by water etc. may cause alterations in the mechanical behaviour of rocks $[17,2]$.

Unlike in other experimental work in porous limestone where cataclastic pore collapse plays an important role in inelastic compaction $[7,8]$, the tested oolitic samples do not show evidence of cataclasis except along the major rupture zones, where gouge material has been observed. This suggests that the pores (small intraparticle pores or small patches of dissolved cement) were shielded by the structure of allochems and prevented their collapse for the most part. Microporosity may have played a role in the failure of the samples, but further studies including scanning electron microscope (SEM) analysis will help to determine that.

Damage in the tested samples is primarily associated with microfracturing. The distribution of the microcrack lengths seems to have a strong dependence on confining stress. The uniaxially tested sample developed longer fractures than those in triaxially tested samples and the highest fracture density. These observations are in agreement with previous results obtained from an experimental study of Indiana limestone [18].

Within triaxially tested samples, those that were submerged for longer time (highest D values) show the highest fracture density (Table 3). As reported from previous authors, microcracks are more easily formed in chemically corroded rocks $[9,2]$. According to several models $[19,4,2]$, in compression tests microcracks may propagate and coalesce developing macrocracks that contribute to the sample failure. This may explain the higher concentration and closer spacing of microfractures close to the main rupture areas, and the lower peak strength achieved by the more damaged samples.

Many extensional cracks in the triaxially tested samples are confined to cemented regions. These fractures radiate from grain-grain or grain-cement contacts likely due to accumulation of stress at grain boundaries. 
However, the relative movement of the rigid allochems with respect to the micrite or sparitic cement may also have played an important role. The rigidity of allochems during deformation is supported by similar axial ratios and the overall grain size in both, weathered and unweathered (fresh) samples. Variations in the orientation of the long axis of allochems (with respect to bedding) in the fresh sample with respect to weathered samples (not shown in this paper) indicate that rigid body rotation was likely a mechanism of deformation in these samples. These observations are similar to earlier investigations of inelastic compaction in allochemical limestones [7, 8].

Twinning is an important mechanism of deformation in the investigated samples (Figure 4). In previous publications, an increase in twinning activity with increasing grain size and stress has been reported [20]. Moreover, an increase in twinning density in limestone has been correlated with strain hardening related to the increase in differential stress $[7,8,21]$. The tested samples are relatively homogeneous in grain size, and although no linear correlation was observed between peak strength and twinning density, petrographic observations and semiquantitative data show an overall trend of increasing twinning density with immersion time. In fact, the results show that fracture and twinning density values for the samples immersed for 50 days are similar. This suggests that $\mathrm{pH}$ is not the main factor in weakening the samples and that long periods of exposure constitute an important factor in the process of rock softening that likely allowed the less-rigid samples (lower Young's moduli) to accommodate part of the inelastic strain through plastic deformation (twinning) before failure. Since these observations are based on a limited number of samples, further systematic investigations are being implemented to assess the extent of these results.

\section{Conclusions}

The microstructural damage after uniaxial compression test on a fresh sample was compared with that of samples tested triaxially after being submerged in $\mathrm{pH} 3$ and $\mathrm{pH} 5$ solutions for 30 and 50 days durations. Based on the tests and observations, the following conclusions are drawn:

- A general increase of the change in effective porosity and decrease of the Young modulus with immersion time. The peak strength decreased with increasing immersion time as well as decreasing $\mathrm{pH}$.

- The main deformation mechanisms observed were micro fracturing and twinning. The density of microfractures and twinning increased with exposure duration. In general, the exposure period seems to be the critical factor in the observed chemically induced damage that lead to a higher degradation of the mechanical properties in the samples.

- Cataclastic damage was not observed outside of the main rupture plane. Nor was pore collapse observed, likely due to the small size of the pores in the samples. In contrast, grain boundaries were the dominant stressconcentrators, from which microcracks (mainly aligned with $\sigma_{1}$ ) emanated.
- Samples tested in triaxial compression developed shorter (and mostly localized in cemented areas) fractures compared to the sample tested uniaxially. Although this suggests that microcrack lengths depend on confining pressure, more tests in uniaxial compression and other confining stress conditions are needed to verify this observation.

- Rigid grain rotation likely occurred during compression testing, suggesting mechanical contrast between allochems and cement.

The study of a larger number of samples involving SEM analysis will expand and improve the preliminary observations presented in this work.

\section{References}

1. D. Grgic, A. Giraud, C. Auvray, Impact of chemical weathering on micro/macro-mechanical properties of oolithic iron ore, Int. J. Rock Mech. Min. Sci., 64, 236-245 (2013)

2. H. Li, Z. Zhong, K. I. I. Eshiet, Y. Sheng, X. Liu, D. Yang, Experimental investigation of the permeability and mechanical behaviours of chemically corroded limestone under different unloading conditions, Rock Mech. and Rock Eng. https ://doi.org/10.1007/s00603-019-01961-y (2019)

3. K.P. Zhou, L. Bin, J.L. Li, H.W. Deng, B. Feng, Microscopic damage and dynamic mechanical properties of rock under freeze-thaw environment, Trans Nonferrous Met. Soc. China 25, 1254-1261 (2015)

4. W. Li, X. An, H. Li, Limestone mechanical deformation behavior and failure mechanisms: a review, Acta. Geochim., 37(2), 153-170 (2018)

5. P. Baud, A. Schubnel, T.F. Wong, Dilatancy, compaction, and failure mode in Solnhofen limestone, J. Geophys. Res., 105, 19289-19303 (2000)

6. M. Tufail, K. Shahzada, B. Gencturk, J.Q. Wei, Effect of elevated temperature on mechanical properties of limestone, quartzite and granite concrete, Int. J. Concr. Struct. Mater., 11, 17-28 (2017)

7. V. Vajdova, W. Zhu, T.N. Chen, T.F. Wong, Micromechanics of brittle faulting and cataclastic flow in Tavel limestone, J., Struct. Geol., 32, 1158-1169 (2010)

8. V. Vajdova, P. Baud, L. Wu, T.F. Wong, Micromechanics of inelastic compaction in two allochemical limestones, J. Struct. Geol. 43, 100-117 (2012)

9. X.T. Feng, W.X. Ding, Experimental study of limestone micro-fracturing under a coupled stress, fluid flow and changing chemical environment, Int. J. Rock Mech. Min. Sci., 44, 437-448 (2007)

10. D. Grgic, Influence of $\mathrm{CO}_{2}$ on the long-term chemomechanical behavior of an oolitic limestone, $J$. Geophys. Res., 116, 1-22 (2011)

11. D. Croizé, K. Bjørlykke, J. Jahren, F. Renard, Experimental mechanical and chemical compaction of carbonate sand. J. Geophys. Res. Solid Earth. https://doi.org/10.1029/2010JB007697 (2010) 
12. A. Nicolas, J. Fortin, J.B. Regnet, B.A. Verberne, O. Plumper, A. Dimanov, C.J. Spiers, Y. Gueguen, Brittle and semibrittle creep of Tavel limestone deformed at room temperature, J. Geophys. Res., 122, 4436-4459 (2017)

13. D.D. Carr, Geometry and origin of oolite bodies in the Ste. Genevieve Limestone (Mississipian) in the Illinois Basin, Bulletin 48, Indiana Geological Survey, 81p. (1973)

14. H.H. Gray, Physiographic divisions of Indiana, Indiana Geological Survey Special Report, 61 (2000)

15. R.L. Folk, Practical petrographic classification of limestones, AAPG Bull., 43, 1e38 (1959)

16. L.M. Kachanov, Rupture time under creep conditions, Int. J. Fract., 97(1-4), 11-8 (1999)

17. A.C. Lasaga, Chemical kinetics of water-rock interactions, J. Geophys. Res. Solid Earth, 89, 4009-4025 (1984)

18. Z. Zheng, N. G. W. Cook, L. R. Myer, Stress induced microcrack geometry at failure in unconfined and confined axial compressive tests, Proc. U. S. Rock Mech. Symp., 30, 749- 756 (1989)

19. Z. Reches, D. A. Lockner, Nucleation and growth of faults in brittle rocks, J. Geophys. Res., 99, 18,159 - 18,174 (1994)

20. K.J. Rowe, E.H. Rutter, Paleostress estimation using calcite twinning: experimental calibration and application to nature, J. Struct. Geol., 12, 1e17 (1990)

21. C. Parlangeau, A. Dimanov, O. Lacombe, S. Hallais, J.M. Daniel, Uniaxial compression of calcite single crystals at room temperature: insights into twinning activation and development, Solid Earth 10, 307-316, https://doi.org/10.5194/se-10-307-2019 (2019) 